\title{
Microplate Assay to Study Carboxypeptidase A Inhibition in Andean Potatoes
}

Mariana Edith Tellechea1, 2, \# Javier Garcia-Pardo1, \#, Juliana Cotabarren², Daniela Lufrano², Laura

Bakas $^{2}$, Francesc Xavier Avilés ${ }^{1}$, Walter David Obregon², Julia Lorenzo ${ }^{1, *}$ and Sebastián Tanco ${ }^{3,4, *}$

${ }^{1}$ Institut de Biotecnologia i de Biomedicina and Departament de Bioquímica i Biologia Molecular, Universitat Autònoma de Barcelona, Campus Universitari, Bellaterra, Cerdanyola del Vallès, Barcelona, Spain; ${ }^{2}$ Centro de Investigación de Proteínas Vegetales, Departamento de Ciencias Biológicas, Facultad de Ciencias Exactas, Universidad Nacional de La Plata, La Plata, Argentina; ${ }^{3}$ Medical Biotechnology Center, VIB, Ghent, Belgium; 'Department of Biochemistry, Ghent University, Ghent, Belgium

*For correspondence: julia.lorenzo@uab.es; sebastian.tanco@vib-ugent.be

\#Contributed equally to this work

[Abstract] Metallocarboxypeptidases (MCP) are zinc-dependent exopeptidases that catalyze the hydrolysis of C-terminal amide bonds in proteins and peptides. They are involved in a wide range of physiological processes and have recently emerged as relevant drug targets in biomedicine (Arolas et al., 2007). In this context, the study and discovery of new MCP inhibitors from plants constitute a valuable approach for the development of new therapeutic strategies. Herein we describe a simple and accessible microplate method for the study of the specific and dose-response carboxypeptidase A inhibitory activities present in Andean potato tubers. Our protocol combines an extraction method optimized for small protein inhibitors in plant tissues, with the measurement of enzyme kinetics using a microplate reader. These instruments are capable of reading small sample volumes, for many samples in a very short time-frame, therefore reducing the time and costs of high-throughput screening experiments. Although this protocol describes the study of Andean potatoes, our approach is also applicable to the analysis other plant samples.

Keywords: Metallocarboxypeptidase, Carboxypeptidase A, Inhibitor, Inhibitory activity, Microplate assay, Potatoes

[Background] In higher plants, small proteinaceous protease inhibitors are wound-induced molecules produced as a part of its defense system against insect attack (Graham et al., 1981; Villanueva et al., 1998). Among the studied inhibitors, only two are specific for MCP, i.e., the potato carboxypeptidase inhibitor $(\mathrm{PCl})$ and its close homolog found in tomato plants $(\mathrm{TCl})$. Over the last few decades, the presence of MCP inhibitors in Solanaceae has been extensively reported, revealing potato (Solanum tuberosum) as one of the most important sources of MCP inhibitors (Hass et al., 1979; Obregón et al., 2012; Lufrano et al., 2015). In humans, MCP action is exquisitely regulated and dysregulation of its function might lead to disease or even to cell death (Arolas et al., 2007). In fact, MCP have been associated with human pathologies such as acute pancreatitis (Appelros et al., 1998), diabetes (Cool et al., 1997), several types of cancer (Ross et al., 2009; Sun et al., 2016; Abdelmagid et al., 2008; Tsakiris 
et al., 2008), fibrinolysis (Valnickova et al., 2007), inflammation (Deiteren et al., 2009) or neurodegeneration (Rogowski et al., 2010). In this context, there is an interest in the discovery of new MCP inhibitors, and thus we focus our studies in potatoes that are native from the Andean region of South America. In this region, thousands of different potato varieties coexist, constituting a natural reservoir for the discovery of novel MCP inhibitors (Figure 1).

A

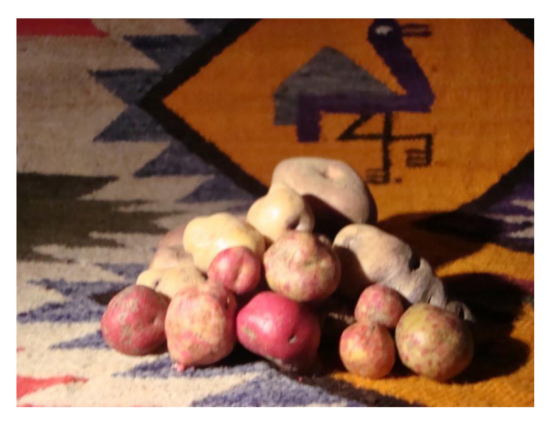

B

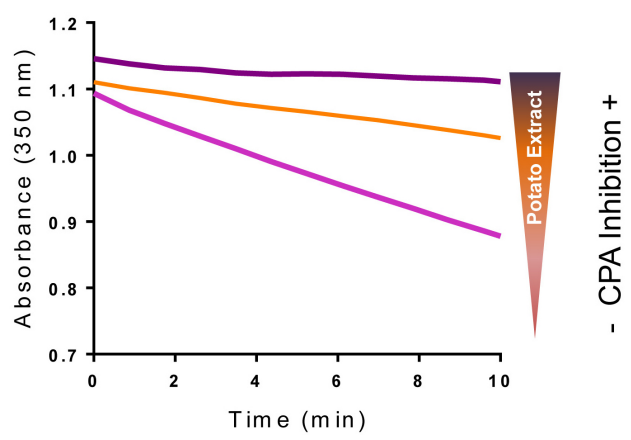

Figure 1. Andean potatoes and potato extract CPA inhibitory activity. A. Picture displaying the large number of potato varieties found within the Andean region. Currently in this region coexist thousands of Andean varieties of Solanum tuberosum (Machida-Hirano, 2015; Clausen et al., 2010). B. Effects of potato extracts on bCPA activity. The activity of bovine CPA (bCPA) was measured using the substrate $\mathrm{N}$-(4-methoxyphenylazoformyl)-Phe-OH determining the decrease in absorbance at $340 \mathrm{~nm}$ in function of the time. Due to its high content in MCP inhibitors, the addition of potato extract to the reaction decreases the rate of substrate hydrolysis in a dose-response manner.

Here, we describe a simple protocol to determine the specific and dose-response carboxypeptidase A inhibitory activity present in Andean potatoes and in other biological extracts using microplates. The major advantage of this protocol over other available approaches (Yanes et al., 2007) is that the use of microplates allows multiple enzymatic measurements to be done in a single experiment, therefore reducing the time and costs.

\section{Materials and Reagents}

1. $50 \mathrm{ml}$ tubes

2. 96-well microplates, clear flat bottom (Corning, catalog number: 3364 )

3. Syringe filters, $0.45 \mu \mathrm{m}$ pore size (EMD Millipore, catalog number: SLHP033RS)

4. Potato tubers

5. General laboratory materials and instrumentation (e.g., micropipettes, microtubes, tips)

6. Bradford assay kit, e.g., Coomassie Plus Assay Kit (Thermo Fisher Scientific, Thermo Scientific ${ }^{\top M}$, catalog number: 23236)

7. Bovine serum albumin (BSA) 
8. N-(4-methoxyphenylazoformyl)-Phe-OH·potassium salt (Bachem, catalog number: M-2245)

9. Trizma $^{\circledR}$ base (Sigma-Aldrich, catalog number: T1503)

10. Sodium chloride ( $\mathrm{NaCl}$ ) (Sigma-Aldrich, catalog number: S7653)

11. Hydrochloric acid ( $\mathrm{HCl})$ (Sigma-Aldrich, catalog number: 258148)

12. Dimethyl sulfoxide (DMSO) (Sigma-Aldrich, catalog number: D4540)

13. Bovine carboxypeptidase A (bCPA) (Sigma-Aldrich, catalog number: C9268)

14. Carboxypeptidase A reaction buffer/Extraction buffer (see Recipes)

15. $2 \mathrm{mg} / \mathrm{ml}$ bCPA stock solution (see Recipes)

16. 10x bCPA working solution (see Recipes)

17. $1,000 x$ substrate stock solution (see Recipes)

18. $10 x$ substrate working solution (see Recipes)

\section{Equipment}

1. Laboratory blender or equivalent (Oster, catalog number: 004093-008-NP0)

2. Refrigerated centrifuge (suitable for volumes of $50 \mathrm{ml}$ ) (Beckman Coulter, model: Avanti J-26 $\mathrm{XPI})$

3. UV-Vis microplate spectrophotometer system capable of operating at 340 and $595 \mathrm{~nm}$ (e.g., PerkinEImer, model: Victor $X 2030-0050$ or other equivalent spectrophotometer)

4. pH meter (HACH LANGE SPAIN, Crison, model: GLP 21)

5. $37{ }^{\circ} \mathrm{C}$ oven (e.g., Thermo Fisher Scientific, Thermo Scientific ${ }^{\mathrm{TM}}$, model: Heratherm Compact Microbiological Incubator)

6. Multichannel pipette (e.g., Technology Networks, model: CappAero Multichannel Pippete 25$200 \mu \mathrm{l})$

\section{Software}

1. GraphPad Prism 5 software (GraphPad Software, Ing USA)

\section{Procedure}

A. Preparation of Andean potato extracts and protein quantification

1. Wash two mature potato tubers (stage five, according to Johnson, 2008) with distilled water. Peel, weigh (in our case $11.50 \mathrm{~g}$ ) and dice them into small pieces of about $2 \times 2 \mathrm{~cm}$ in size (see Figures $2 \mathrm{~A}$ and $2 \mathrm{~B})$. 


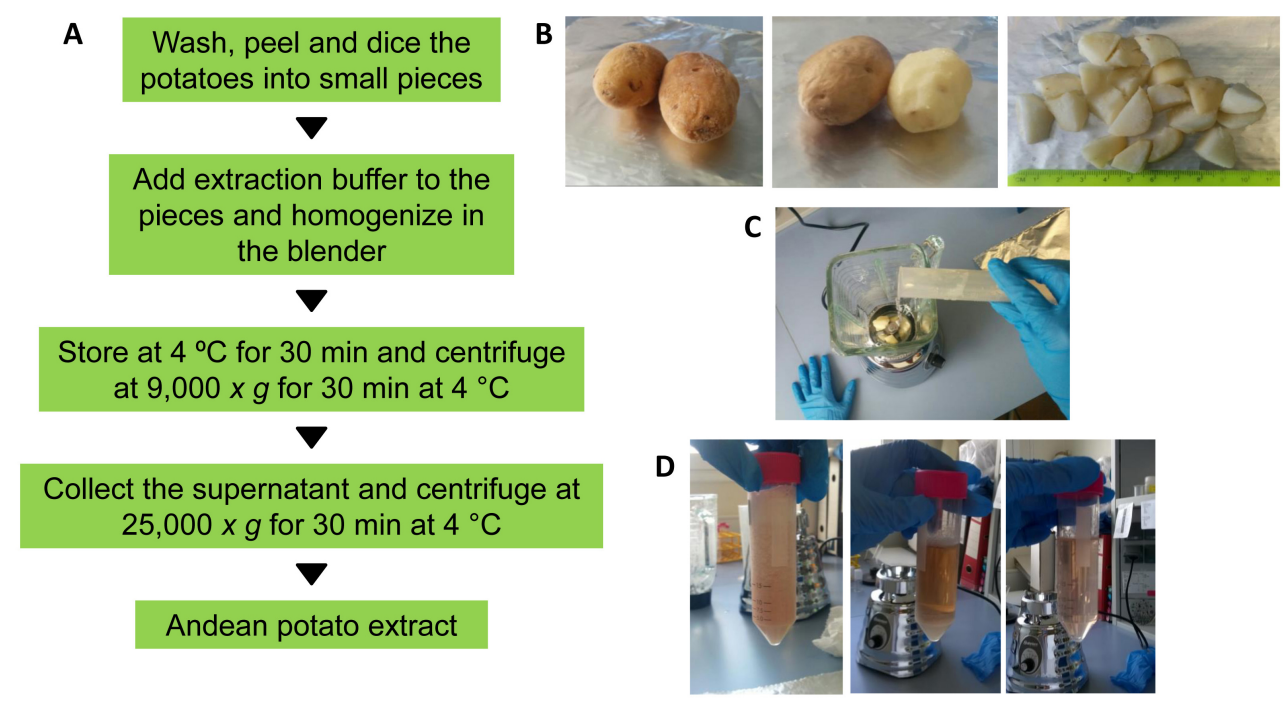

Figure 2. Preparation of potato extracts. A. Workflow followed to obtain the crude potato extract enriched in MCP inhibitors. B. Potato peeling and dicing. C. Mixing of the diced potatoes with the extraction buffer into the blender. $D$. The appearance of the potato extract before and after two centrifugation steps (from left to right).

2. Mix the potato pieces with three volumes of ice-cold extraction buffer (in our case $34.50 \mathrm{ml}$; a mass/volume ratio of 1:3) into the cooled blender and homogenize at gentle speed for $5 \mathrm{~min}$ (Figures 2A and 2C).

Note: The homogenization should be performed in several sessions of 15-30 sec each, with 60 sec intervals between sessions to prevent excessive heating of the sample.

3. After homogenization, transfer the potato homogenate to $50 \mathrm{ml}$ tubes and centrifuge the sample at $9,000 \times g$ for $30 \mathrm{~min}$ at $4{ }^{\circ} \mathrm{C}$.

4. Transfer the supernatant to a clean $50 \mathrm{ml}$ centrifuge tube and spin at $25,000 \times \mathrm{g}$ for $30 \mathrm{~min}$ at $4{ }^{\circ} \mathrm{C}$ (Figures 2A and 2D). After the second centrifugation step, collect the resultant supernatant and filter through a $0.45 \mu \mathrm{m}$ syringe filter to eliminate protein aggregates. The resultant potato extract can be stored at $-20^{\circ} \mathrm{C}$ until analyzed.

5. Determine the protein concentration of the samples using the Coomassie Plus Assay Kit, according to the manufacturer's instructions. In brief, prepare a final volume of $500 \mu \mathrm{l}$ of each of the six standard solutions containing $0,2,5,10,15$ and $20 \mu \mathrm{g} / \mathrm{ml}$ of BSA and appropriate dilutions of the sample/s. Transfer $150 \mu \mathrm{l}$ of each standard and potato extract samples into different wells of a 96-well microplate. BSA standards and potato extract samples should be assayed in triplicate. Then, add $150 \mu \mathrm{l}$ of the Coomassie Plus reagent (see Materials and Reagents section) to each well and mix using the micropipette, by pipetting up and down carefully. After $5 \mathrm{~min}$ incubation at room temperature, measure the absorbance at $595 \mathrm{~nm}$ using a UV-Vis microplate spectrophotometer. Typically, we obtained $1-2 \mathrm{mg} / \mathrm{ml}$ of protein in the extracts. 


\section{B. Enzymatic assays}

1. Determination of bCPA specific inhibitory activity

a. Prepare triplicates of the reaction mixtures (Table 1) in a microplate without adding the substrate. Calculate the volume of potato extract to be added, in order to obtain $20 \%$ to $80 \%$ of bCPA inhibition. To obtain these inhibition levels, we typically add around $5-30 \mu \mathrm{g} / \mathrm{ml}$ of final protein concentration to the assay.

Table 1. Reaction mixture

\begin{tabular}{lcc}
\hline & Control reaction & Reaction + potato extract \\
\hline bCPA reaction buffer $(\mu \mathrm{l})$ & 200 & $200-\mathrm{X}$ \\
Enzyme working solution $(\boldsymbol{\mu l})$ & 25 & 25 \\
Potato extract $(\mu \mathrm{l})$ & - & $X$ \\
Substrate $(\mu \mathrm{l})$ & 25 & 25 \\
Final reaction volume $(\mu \mathrm{l})$ & 250 & 250 \\
\hline
\end{tabular}

Where $\mathrm{X}$ is the volume (in $\mu \mathrm{l}$ ) of potato extract to be assayed. The substrate should be added immediately before plate reading (see step B1c below).

b. Cover the microplate with a lid and incubate at $37^{\circ} \mathrm{C}$ for $15 \mathrm{~min}$.

c. Add $25 \mu \mathrm{l}$ of substrate working solution to each well, mix carefully and thoroughly, by pipetting up and down carefully with a multichannel micropipette (A graphical demonstration of steps B1a, B1b and B1c is shown in Video 1).

Note: the homogenization should be performed in no longer than $60 \mathrm{sec}$, to avoid significant consumption of the substrate before absorbance monitoring.

d. Perform absorbance measurements at $340 \mathrm{~nm}$ every $30 \mathrm{sec}$ for $10 \mathrm{~min}$.

e. One unit of inhibitory activity is defined as the amount of inhibitor able to reduce one unit of bCPA activity, which in turn corresponds to the amount of enzyme that hydrolyzes $1.0 \mu \mathrm{mol}$ of $\mathrm{N}$-(4-methoxyphenylazoformyl)-Phe-OH per min at $25^{\circ} \mathrm{C}$. Consequently, Equation 1 can be used to calculate the Specific Inhibitory Activity (SIA) found in potato extracts.

Equation 1:

$$
I A(U / m l)=\left(\left(\frac{\Delta A b s(340 \mathrm{~nm})}{\Delta t(\mathrm{~min})}\right)_{\text {Control }}-\left(\frac{\Delta A b s(340 \mathrm{~nm})}{\Delta t(\mathrm{~min})}\right)_{\text {Potato ext }} \frac{1}{\xi} \frac{V_{\text {total }}}{V_{\text {Potato ext. }}} \frac{D}{L}\right)
$$

Where,

IA is the Inhibitory Activity in $\mathrm{U} / \mathrm{ml}$,

$\Delta \mathrm{Abs} / \Delta \mathrm{t}$ is the absorbance variation per unit of time (in $\mathrm{min}$ ) during the reaction in absence (control), and in presence of the potato extract (Potato ext), respectively,

$\xi$ is the extinction coefficient for the substrate $\mathrm{N}$-(4-methoxyphenylazoformyl)-Phe-OH ( $\xi$ $350 \mathrm{~nm}=19\left[\mu \mathrm{moles} / \mathrm{ml}^{-1} \mathrm{~cm}^{-1}\right)$,

$V_{\text {total }}$ is the assay volume and $V_{\text {Potato ext }}$ is the volume of extract added to the reaction, 
$D$ and $L$ are the dilution factor for the extract and the path length (in $\mathrm{cm}$ ), respectively. Typically, the path length in a microplate for a volume of $250 \mu \mathrm{l}$ is $0.7 \mathrm{~cm}$. However, for different reaction volumes, or for a more accurate calculation, check your 96-well microplate manufacturer instructions.

Then, calculate directly the SIA by dividing the resultant IA value by the protein concentration of the sample in $\mathrm{mg} / \mathrm{ml}$ (see Equation 2 and examples in Table 2).

Equation 2:

$$
S I A=\frac{I A}{[\text { Protein }]_{\text {Potato Ext }}}
$$

2. Determination of the IC50: Dose-Response curve assay (see Figure 3)

a. Prepare the same control reaction as described in step B1a and prepare at least 12 additional reaction mixtures with different final concentrations of the potato extract in the assay, ranging from 0 to $300 \mu \mathrm{g} / \mathrm{ml}$, (or even with higher concentration to obtain the complete inhibition of bCPA activity).

Note: We typically assay a total of 15 different extract final concentrations, containing 0, 1 , $2,3,5,10,15,20,30,75,100,150,200,250$ and $300 \mu \mathrm{g} / \mathrm{ml}$ of protein.

Fit the results obtained to the following Equation 3 and determine the IC50 value.

Equation 3:

$$
Y=\frac{100}{1+10^{\left(X-\log I C_{50}\right)}}
$$

Where,

$\mathrm{X}$ is the log-transformed protein concentration assayed,

$Y$ is the normalized bCPA activity (relative to the control condition and expressed as a percentage of the maximal activity).

$Y$ values can be calculated for each extract concentration, using the following Equation 4 .

Equation 4:

$$
Y=\frac{\left(\frac{\Delta A b s 340 \mathrm{~nm}}{\Delta t(\mathrm{~min})}\right)_{\text {Potato ext }}}{\left(\frac{\Delta A b s 340 \mathrm{~nm}}{\Delta t(\mathrm{~min})}\right)_{\text {Control }}} \times 100
$$

The IC50 value is the extract concentration necessary to reach a $50 \%$ of bCPA inhibition (Copeland, 2005). See representative examples of dose-response bCPA inhibitory plots in Figure 3 and the corresponding IC50 values in Table 2. 
Dose response curves

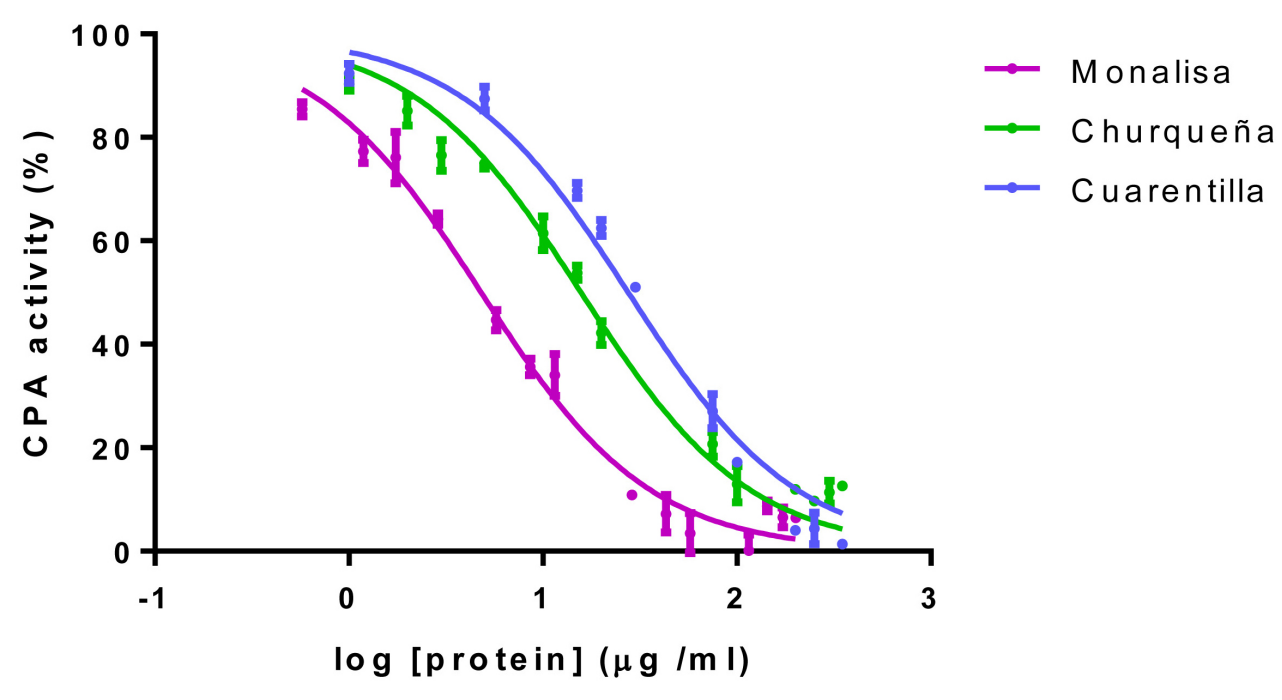

Figure 3. Examples of dose-response inhibitory plots. Representative examples of doseresponse inhibitory curves determined for three different varieties of potatoes; Solanum tuberosum subsp. tuberosum var. monalisa (Monalisa, magenta solid line), Solanum tuberosum subsp. andigenum var. churqueña (Churqueña, green solid line), Solanum tuberosum subsp. andigenum var. cuarentilla; (Cuarentilla, blue solid line).

Table 2. Summary of the inhibitory activities found in different varieties of potatoes

\begin{tabular}{lclll}
\hline Potato specie & $\begin{array}{c}\text { Protein } \\
\text { concentration } \\
(\mathrm{mg} / \mathrm{ml})\end{array}$ & $\begin{array}{c}\text { Inhibitory activity } \\
(\mathrm{mU} / \mathrm{ml})\end{array}$ & $\begin{array}{c}\text { Specific inhibitory } \\
\text { activity }(\mathbf{m U} / \mathrm{mg})\end{array}$ & IC50 $(\boldsymbol{\mu g} / \mathbf{m l})$ \\
\hline A & $1.56 \pm 0.032$ & $3.59 \pm 0.06$ & $2.30 \pm 0.021$ & $4.81 \pm 0.3$ \\
B & $2.71 \pm 0.033$ & $2.07 \pm 0.11$ & $0.76 \pm 0.012$ & $15.73 \pm 0.9$ \\
C & $0.79 \pm 0.014$ & $0.56 \pm 0.06$ & $0.71 \pm 0.018$ & $27.54 \pm 1.8$ \\
\hline
\end{tabular}

A: Solanum tuberosum subsp. tuberosum var. monalisa; B: Solanum tuberosum subsp. andigenum var. churqueña; C: Solanum tuberosum subsp. andigenum var. cuarentilla

The two protocols for the determination of SIA and IC50 are summarized in the scheme of Figure 4 and Video 1. 


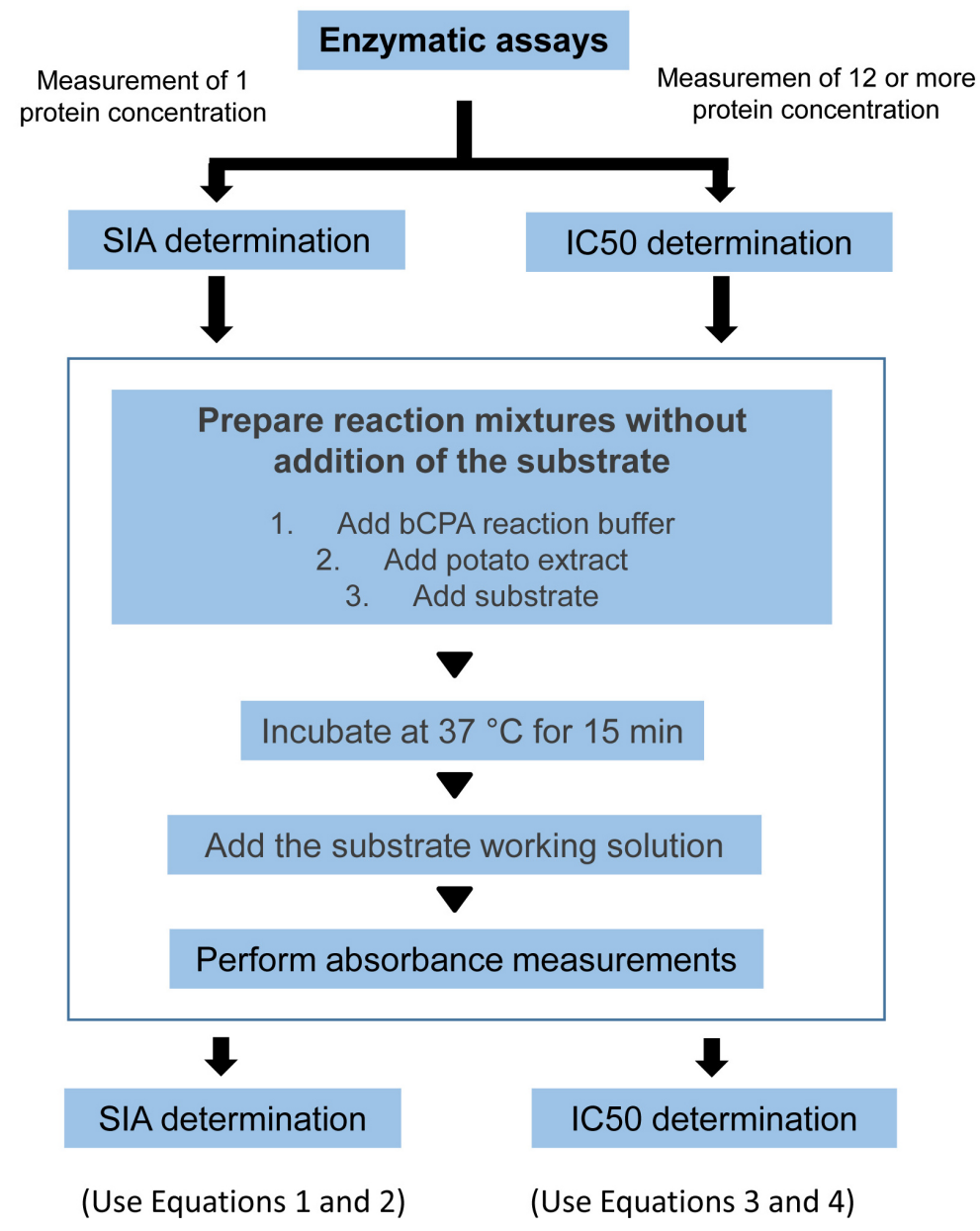

Figure 4. Enzymatic assays. General workflow for the measurement of inhibitory activity and determination of the SIA and IC50.

Video 1. Video demonstration of the protocol to perform the enzymatic measurements

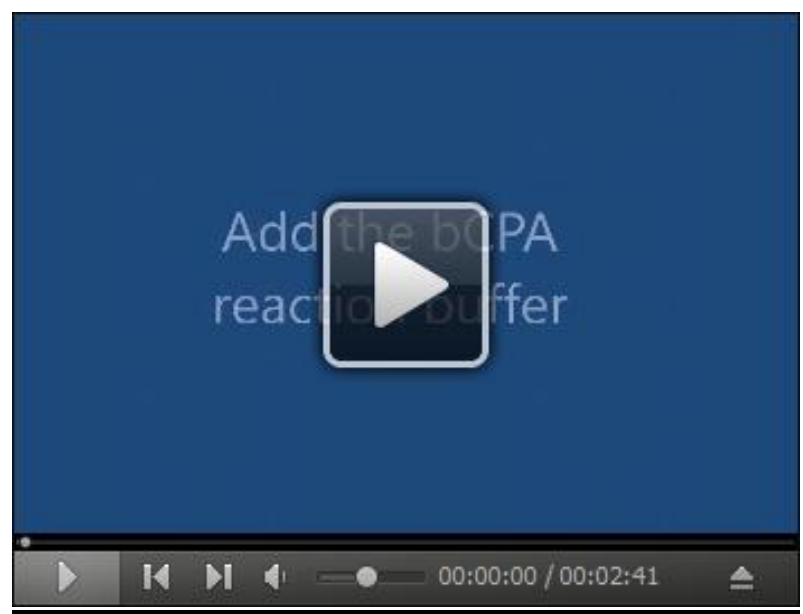




\section{Data analysis}

Data fittings and IC50 determination were performed using GraphPad Prism 5 software (GraphPad Software, Ing USA) (Motulsky et. al., 2007). Only fittings with a $R^{2}>0.97$ were considered.

\section{Notes}

1. Freshly collected samples display higher inhibitory activities; however, frozen samples can also be used.

2. The protocol described here is suitable for any scale of sample preparation, therefore volumes and reagent quantities should be scaled proportionally.

3. Here we used a laboratory blender that allows a complete sample blending and homogenization. Alternatively, other appropriate homogenization systems can be used.

4. The soluble fraction resultant from the step A4 is a crude extract rich in MCP inhibitors. Other proteinaceous and chemical compounds soluble in the homogenization buffer can be also present in the sample. For a higher MCP inhibitor enrichment (e.g., for Ki determination), further purification procedures could be addressed (Pearce and Ryan, 1983).

5. We used a commercial Bradford assay kit; however, non-commercial Bradford reagents or other different quantification assays can be used (Bradford, 1976; He, 2011a and 2011b).

6. The microplate reactions can alternatively be performed in conventional spectrophotometer cuvettes by scaling up the reagents proportionately.

7. Mix the enzyme suspension thoroughly to ensure complete mixing. It is strongly recommended to follow manufacturer's instructions for an accurate enzyme preparation.

8. The substrate concentration used is such that the enzyme is at the maximum velocity. The enzyme concentration might be adjusted to consume less than $5-10 \%$ of substrate.

\section{$\underline{\text { Recipes }}$}

1. Carboxypeptidase A reaction buffer/Extraction buffer (1 L, $20 \mathrm{mM}$ Tris- $\mathrm{HCl}, 500 \mathrm{mM} \mathrm{NaCl}, \mathrm{pH}$ 7.5)

$2.42 \mathrm{~g}$ of Trizma base

$29.22 \mathrm{~g}$ of $\mathrm{NaCl}$

MilliQ water up to $900 \mathrm{ml}$

Adjust solution to $\mathrm{pH} 7.5$ by addition of $5 \mathrm{~N} \mathrm{HCl}$

Adjust the final volume with MilliQ water to $1,000 \mathrm{ml}$

Store at $4{ }^{\circ} \mathrm{C}$ up to two weeks

2. $2 \mathrm{mg} / \mathrm{ml}$ bCPA stock solution

Prepare $1 \mathrm{ml}$ of a $2 \mathrm{mg} / \mathrm{ml}$ bCPA solution $(\sim 57 \mu \mathrm{M})$ in reaction buffer

Note: We typically dilute $100 \mu$ of commercial bCPA with $900 \mu$ l of carboxypeptidase A reaction 
buffer. Note that different batches of bCPA may have different enzyme concentrations, therefore the dilutions should be adjusted accordingly.

Divide into $20 \mu \mathrm{l}$ aliquots

For short-term storage, store at $4{ }^{\circ} \mathrm{C}$; for long-term storage, store at $-20{ }^{\circ} \mathrm{C}$

3. 10x bCPA working solution

Prepare $10 \mathrm{ml}$ of a $50 \mathrm{nM}$ enzyme solution by diluting $8.77 \mu \mathrm{l}$ of bCPA stock solution in 9.991 $\mathrm{ml}$ of carboxypeptidase A reaction buffer

For short-term storage, store at $4{ }^{\circ} \mathrm{C}$; for long-term storage, store at $-20{ }^{\circ} \mathrm{C}$

4. 1,000x substrate stock solution (100 mM N-[4-methoxyphenylazoformyl]-Phe-OH)

Dissolve $100 \mathrm{mg}$ of $\mathrm{N}$-(4-methoxyphenylazoformyl)-Phe-OH·potassium salt (Mock et al., 1996) in $2.74 \mathrm{ml}$ of DMSO

Divide into $100 \mu \mathrm{l}$ aliquots and store at $-20^{\circ} \mathrm{C}$

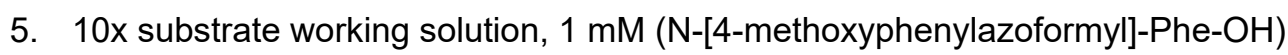

Dilute $100 \mu \mathrm{l}$ of the substrate stock solution to a final volume of $10 \mathrm{ml}$ with carboxypeptidase $A$ reaction buffer

Store at $-20^{\circ} \mathrm{C}$

\section{Acknowledgments}

The protocol described here was adapted from previously published studies (Covaleda et al., 2012; Lufrano et al., 2015; Sanglas et al., 2009). This work was supported by the Spanish Ministry of Innovation and Competitiveness grant BIO2013-44973-R and by UNLP, Argentina grant PPID/X014. The authors acknowledge support of the CONICET (PIP 0120), Universidad Nacional de La Plata (UNLP), PPID X/014, Bilateral Cooperation Program MinCyT-MICINN (project ES/09/24AR2009/006) and Proyectos Redes Universitarias, PPUA, SPU, Argentina.

\section{References}

1. Abdelmagid, S. A. and Too, C. K. (2008). Prolactin and estrogen up-regulate carboxypeptidase$\mathrm{d}$ to promote nitric oxide production and survival of MCF-7 breast cancer cells. Endocrinology 149(10): 4821-8.

2. Appelros, S., Thim, L. and Borgstrom, A. (1998). Activation peptide of carboxypeptidase B in serum and urine in acute pancreatitis. Gut 42(1): 97-102.

3. Arolas, J. L., Vendrell, J., Aviles, F. X. and Fricker, L. D. (2007). Metallocarboxypeptidases: emerging drug targets in biomedicine. Curr Pharm Des 13(4): 349-366.

4. Bradford, M. M. (1976). A rapid and sensitive method for the quantitation of microgram quantities of protein utilizing the principle of protein-dye binding. Anal Biochem 72: 248-254.

5. Clausen, A. M., Ispizúa, N. and Digilio. (2010). Native andean potato varieties in argentina: conservation and evaluation of an endangered genetic resource contents. AmJPSB 3(1): 72-82. 
6. Cool D. R., Normant E., Shen F., Chen H. C., Pannell L., Zhang Y. and Loh Y. P. (1997). Carboxypeptidase $\mathrm{E}$ is a regulated secretory pathway sorting receptor: genetic obliteration leads to endocrine disorders in $\mathrm{Cpe}^{\text {fat }}$ mice. Cell 88(1): 73-83.

7. Copeland R. (2005). Lead optimization and SAR for reversible inhibitors. In: Copeland R. (Ed). Evaluation of enzyme inhibitors in drug discovery: a guide for medicinal chemists and pharmacologists. John Wiley \& Sons, pp: 125-128.

8. Covaleda, G., del Rivero, M. A., Chavez, M. A., Aviles, F. X. and Reverter, D. (2012). Crystal structure of novel metallocarboxypeptidase inhibitor from marine mollusk Nerita versicolor in complex with human carboxypeptidase A4. J Biol Chem 287(12): 9250-9258.

9. Deiteren, K., Hendriks, D., Scharpe, S. and Lambeir, A. M. (2009). Carboxypeptidase M: Multiple alliances and unknown partners. Clin Chim Acta 399(1-2): 24-39.

10. Graham, J. S. and Ryan, C. A. (1981). Accumulation of a metallo-carboxypeptidase inhibitor in leaves of wounded potato plants. Biochem Biophys Res Commun 101(4): 1164-1170.

11. Hass, G. M. and Derr, J. E. (1979). Purification and characterization of the carboxypeptidase isoinhibitors from potatoes. Plant Physiol 64(6): 1022-1028.

12. He, F. (2011a). Bradford protein assay. Bio-protocol Bio101: e45.

13. He, F. (2011b). BCA (bicinchoninic acid) protein assay. Bio-protocol Bio101: e44.

14. Johnson, D. A. (2008). Potato Health Management ( $2^{\text {nd }}$ ed.). American Phytopathology Society.

15. Lufrano, D., Cotabarren, J., Garcia-Pardo, J., Fernandez-Alvarez, R., Tort, O., Tanco, S., Aviles, F. X., Lorenzo, J. and Obregon, W. D. (2015). Biochemical characterization of a novel carboxypeptidase inhibitor from a variety of Andean potatoes. Phytochemistry 120: 36-45.

16. Machida-Hirano, R. (2015). Diversity of potato genetic resources. Breed Sci 65(1): 26-40.

17. Mock, W. L., Liu,Y. and Stanford, D. J. (1996). Arazoformyl peptide surrogates as spectrophotometric kinetic assay substrates for carboxypeptidase A. Anal Biochem 239(2): 218222.

18. Motulsky, H. (2007). Prism 5 statistics guide. GraphPad Software.

19. Obregón, W. D.; Ghiano, N; Tellechea, M., Cisneros, S., Lazza, C. M.; López, L.M.I. and F. X. Avilés (2012). Detection and characterization of a new metallocarboxypeptidase inhibitor from Solanum tuberosum cv. Desirèe using proteomic techniques. Food Chem 133(4): 1063-1068.

20. Pearce, G. and Ryan, C. A. (1983). A rapid, large-scale method for purification of the metallocarboxypeptidase inhibitor from potato tubers. Anal Biochem 130(1): 223-225.

21. Rogowski, K., van Dijk, J., Magiera, M.M., Bosc, C., Deloulme, J.C., Bosson, A., Peris, L., Gold, N.D., Lacroix, B., Bosch Grau, M., Bec, N., Larroque, C., Desagher, S., Holzer, M., Andrieux, A., Moutin, M.J. and Janke, C. (2010). A family of protein-deglutamylating enzymes associated with neurodegeneration. Cell 143(4): 564-578.

22. Ross P. L., Cheng I., Liu X., Cicek M. S., Carroll P. R., Casey G. and Witte J. S. (2009). Carboxypeptidase 4 gene variants and early-onset intermediate-to-high risk prostate cancer. BMC Cancer 9: 69. 
23. Sanglas, L., Aviles, F. X., Huber, R., Gomis-Ruth, F. X. and Arolas, J. L. (2009). Mammalian metallopeptidase inhibition at the defense barrier of Ascaris parasite. Proc Natl Acad Sci U S A 106(6): 1743-1747.

24. Sun, L., Wang, Y., Yuan, H., Burnett, J., Pan, J., Yang, Z., Ran, Y., Myers, I. and Sun, D. (2016). CPA4 is a novel diagnostic and prognostic marker for human Non-Small-Cell lung cancer. $J$ Cancer 7(10):1197-204.

25. Tsakiris I., Soos G., Nemes Z., Kiss S. S., Andras C., Szanto J. and Dezso B. (2008). The presence of carboxypeptidase-M in tumour cells signifies epidermal growth factor receptor expression in lung adenocarcinomas: the coexistence predicts a poor prognosis regardless of EGFR levels. J Cancer Res Clin Oncol 134(4): 439-451.

26. Valnickova, Z., Thogersen, I. B., Potempa, J. and Enghild, J. J. (2007). Thrombin-activable fibrinolysis inhibitor (TAFI) zymogen is an active carboxypeptidase. $J$ Biol Chem 282(5): 30663076 .

27. Villanueva, J., Canals, F., Prat, S., Ludevid, D., Querol, E. and Aviles, F. X. (1998). Characterization of the wound-induced metallocarboxypeptidase inhibitor from potato cDNA sequence, induction of gene expression, subcellular immunolocalization and potential roles of the C-terminal propeptide. FEBS Lett 440(1-2): 175-182.

28. Yanes, O., Villanueva, J., Querol, E. and Aviles, F. (2007). Enzymatic measurements for the detection of trypsin and carboxypeptidase A inhibitory activity. Protocol Exchange. 